\title{
Assessment of the relation of serum iron and ferritin levels to isokinetic muscle strength in elite athletes without anemia
}

\author{
Tuğba KOCAHAN ${ }^{1}$, Aydın BALCI ${ }^{2}$, Bihter AKINOĞLU ${ }^{3}$, Salih SARI ${ }^{1}$, Adnan HASANOĞLU1
}

${ }^{1}$ Department of Health Services, Center of Athlete Training and Health Research, Sports General Directorship, The Ministry of Youth and Sports, Ankara, Turkiye.

${ }^{2}$ Department of Sports Medicine, School of Medicine, Yildirim Beyazit University Yenimahalle Training and Research Hospital, Ankara, Turkiye.

${ }^{3}$ Department of Physiotherapy and Rehabilitation, Faculty of Health Sciences, Ankara Yıldırım Beyazıt University, Ankara, Turkiye.

\section{SUMMARY}

Iron is an important mineral for the human body. In case of iron deficiency, problems in energy production and utilization occur: The energy required during exercise, and therefore the performance, is related to body iron levels. This study was performed to determine the relationship between isokinetic muscle strength and serum iron and ferritin levels. A total of 278 nonanemic elite athletes were included in the study. Serum iron and ferritin levels were determined, and the relationship between these levels and the results of isokinetic muscle strength measurements was investigated using Spearman correlation test. The relationship between the serum iron levels and isokinetic muscle strength was found to be statistically negligible $(P>0.05)$. However, ferritin levels were correlated with isokinetic muscle strength values $(P<$ 0.05). In conclusion, iron was found to be associated with performance in athletes without anemia.

Key words: Ferritin, iron, isokinetic muscle strength, serum iron, sport performance

\section{INTRODUCTION}

Iron is a vital mineral for the human body. It is involved in oxygen transport, antioxidant defense reactions, and electron transport chain of oxidative phosphorylation $(1,2)$. About $80 \%$ of the iron is actively used (hemoglobin, myoglobin, enzymes, and so forth), and the remaining is stored as an inactive iron depot in the human body (2). The most important regulator of this balance is the peptide-structured hormone"hepcidin" (3). Hepcidin reduces iron absorption from enterocytes and inhibits iron mobilization from macrophages and liver deposits to plasma (3). This balance can be deteriorated by a variety of factors, and iron deficiency may occur. Iron deficiency is common in both the normal population and the athletes (4). Lack of dietary intake, blood loss, and inadequate absorption due to gastrointestinal system pathologies can cause iron deficiency (5). Iron deficiency is more common in women due to menstrual losses (5). Besides, high-intensity exercise increases hepcidin levels and these high levels can lead to iron deficiency (6-8).

Several tests are used to identify iron deficiency, including hemoglobin ( $\mathrm{Hb})$, mean cellular volume, mean cellular hemoglobin, serum iron, and ferritin (2). According to the severity of the deficit, the clinical status is defined as iron deficiency or iron deficiency anemia.

Performance parameters such as aerobic capacity, muscle strength, fatigue, and recovery after exercise are negatively affected by iron deficiency $(2,9)$. Some of the studies in the literature showed that these parameters are affected without anemia (10-13). Hence, it was suggested that the lower limit of normal iron levels of athletes should be higher than that of other individuals (2).

The aim of this study was to determine the associations of "serum iron" and "ferritin"levels with isokinetic muscle strength in nonanemic elite athletes so as to emphasize the importance of iron levels without anemia in sport performance. 


\section{MATERIALS AND METHODS}

Participants were selected from athletes who were in the camp with their national teams. A total of 278 elite nonanemic athletes without musculoskeletal problems, who had not exercised in the last $24 \mathrm{~h}$, were included in the study. The distribution of participants according to their gender and branches is shown in Table 1. This study was designed according to the Declaration of Helsinki and approved by Yıldırım Beyazıt University School of Medicine Ethical Committee. All participants were fully informed about the study, and they all signed written informed consent.

Fasting blood samples were collected from the antecubital vein using two evacuated tubes [one containing EDTA and the other glued tube with a clot activator (SST II Advance)]. After collection, the blood samples were assessed for $\mathrm{Hb}$ and serum iron and ferritin. SYSMEX CBC XT2000I and Bio-System A25 machines were used for the analysis.

Isokinetic muscle strength measurements were performed on participants without anemia and musculoskeletal complaints. Measurements were applied to the participant's dominant leg knee flexor and extensor muscles at $60 \% / \mathrm{s}$ and $180^{\circ} / \mathrm{s}$ velocities.
ISOMED 2000 (D.\&R. Ferstl GmbH, Hemau, Germany) was used for the measurements. The peak torque (PT) values obtained as a result of the measurements were used for statistical analysis.

The distribution of variables was examined using KolmogorovSmirnov test, and the variables were not found to be distributed normally. Spearman correlation test was used to measure the degree of relationship between blood sample results and strength parameters. The level of significance was set at $\alpha=0.05$. SPSS 20.0 was used for data analysis.

\section{RESULTS}

The age, height, weight, and body mass index (BMI) values of the subjects are shown in Table 2. Hb and ferritin and serum iron levels are shown in Table 3. Isokinetic PT values are shown in Table 4.

The relationship between ferritin and PT values of the subjects is shown in Table 5. The athletes' ferritin values were found to be positively correlated with the PT values $(P<0.05)$.

The relationship between serum iron and PT values of the subjects is shown in Table 6 . The serum iron values were found to be moderately positively correlated with PT values $(P<0.05)$.

TABLE 1: Branches and genders of the participants.

\begin{tabular}{llll}
\hline & Male & Female & Total \\
\hline Artistic gymnastics & 22 & 26 & 48 \\
Beach volley & 5 & 8 & 13 \\
Biathlon & 9 & 7 & 16 \\
Boxings & 18 & 0 & 18 \\
Ice hockey & 0 & 14 & 14 \\
Ice skate & 10 & 1 & 11 \\
Soccer & 12 & 0 & 12 \\
Greco-Roman wrestling & 19 & 0 & 19 \\
Judo & 52 & 23 & 75 \\
Rowing & 18 & 11 & 29 \\
Freestyle wrestling & 0 & 22 & 22 \\
Taekwondo & 1 & 0 & 1 \\
Total & 166 & 112 & 278 \\
\hline
\end{tabular}

TABLE 2: Age, height, weight, and BMI of participants.

\begin{tabular}{lll}
\hline & Mean & Standard deviation \\
\hline Age & 19.17 & 4.26 \\
Height $(\mathrm{cm})$ & 169.37 & 13.20 \\
Weight $(\mathrm{kg})$ & 66.60 & 16.38 \\
BMI & 23.39 & 10.24 \\
\hline
\end{tabular}

TABLE 3: $\mathrm{Hb}$ and ferritin and serum iron levels.

\begin{tabular}{lll}
\hline & Mean & Standard deviation \\
\hline $\mathrm{Hb}$ & 13.98 & 1.27 \\
Ferritin & 57.32 & 37.34 \\
Serum Iron & 86.85 & 33.58 \\
\hline
\end{tabular}




\begin{tabular}{lll}
\multicolumn{1}{l}{ TABLE 4: Isokinetic peak torque. } \\
\hline & Mean & Standard deviation \\
\hline $60^{\circ}$ /s Flexion PT & 101.41 & 34.72 \\
$60^{\circ}$ s Extension PT & 190.75 & 61.51 \\
$180^{\circ}$ s Flexion PT & 78.97 & 26.42 \\
$180^{\circ}$ s Extension PT & 128.21 & 39.48 \\
\hline
\end{tabular}

\begin{tabular}{|c|c|c|c|}
\hline & $60 \%$ s Flex $60^{\circ} / \mathrm{s}$ Ext & $180^{\circ} / \mathrm{s}$ Flex & $180^{\circ} / \mathrm{s}$ Ext \\
\hline Correlation C. & $p=0.355^{*} \quad p=0.322^{*}$ & $p=0.333^{*}$ & $p=0.351^{*}$ \\
\hline Significance & $P<0.01 \quad P<0.01$ & $P<0.01$ & $P<0.01$ \\
\hline
\end{tabular}

TABLE 6: Spearman correlation of serum iron and peak torque measurements.

$60 \%$ Flex $60 \%$ s Ext $180 \%$ s Flex $180 \%$ s Ext

Correlation C. $p=0,153^{* *} \quad p=0,186^{* *} p=0,143^{* *} \quad p=0,146^{* *}$

Significance $P=0.011 \quad P=0.002 \quad P=0.017 \quad P=0.015$

**Correlation is significant at the 0.05 level (two-tailed).

Ext: extension; Flex: flexion.

\section{DISCUSSION}

The aim of this study was to determine the association of serum iron and ferritin levels with isokinetic muscle strength in nonanemic elite athletes. The significant findings of this study were as follows:

(1) Serum ferritin levels were found to be weakly correlated with isokinetic muscle strength (14). (2) The relationship between SI and isokinetic muscle strength was found to be negligible (14). The results of the present study were consistent with a study in which iron deficiency was associated with muscle strength without anemia (15).

Several studies investigated the effects of iron levels and iron supplements on sport performance $(16,17)$. In a study involving 15 athletes with iron deficiency, intravenous iron fortification increased ferritin levels but did not have an effect on aerobic capacity (16). In a study of nonanemic female athletes with iron deficiency, iron supplementation increased ferritin levels but did not have any effect on fatigue (17). Studies suggesting that iron supplements do not have a meaningful effect on performance support the weak correlation between ferritin levels and sport performance.

However, some studies support the correlation between iron levels and sport performance. In a study investigating the effect of intravenous iron supplementation on serum ferritin levels and long-distance running performance, the ferritin and V02max values of the participants significantly increased, but this change did not occur in the oral iron supplement group (18). In another study conducted on female rowing athletes, iron supplementation was found to increase ferritin levels and lower lactate response compared with the control group (19). Iron supplementation to sedentary individuals without anemia significantly improved v02max values compared with the control group (12). In another study with 40 elite athletes who did not have anemia, iron supplementation was found to increase ferritin levels and V02max (20).

The aforementioned findings indicate that the relationship between iron levels and athletic performance is controversial. This is probably because that ferritin is an acute-phase reactant and its values change with inflammatory events (21-23). Another reason is thought to be the effect of hepcidin secreted after intense exercise on ferritin levels (6-8). Iron is vital for the contraction of especially slow (oxidative) fibers (24-27). Hence, isokinetic muscle strength was measured in the present study. Differences between types of exercise can be regarded as another reason for differences in the findings (28), which was consistent with the findings of the present study.

In conclusion, body iron levels are thought to be related especially to aerobic exercise performance. Serum ferritin levels, used as body iron indicator, are affected by many factors, thereby influencing the relation of body iron levels to athletic performance.

\section{REFERENCES}

1. Lukaski HC. Vitamin and mineral status: effects on physical performance. Nutrition 2004;20(7):632-44.

2. Clénin G, Cordes M, Huber A, Schumacher YO, Noack P, Scales J, et al. Iron deficiency in sports-definition, influence on performance and therapy. Swiss Med Wkly 2015;145:w14196.

3. Nemeth E, Ganz T. Regulation of iron metabolism by hepcidin. Annu Rev Nutr 2006;26:323-42.

4. Pasricha S-R, Drakesmith H, Black J, Hipgrave D, Biggs B-A. Control of iron deficiency anemia in low-and middle-income countries. Blood 2013;121(14):2607-17. 
5. Peyrin-Biroulet L, Williet N, Cacoub P. Guidelines on the diagnosis and treatment of iron deficiency across indications: a systematic review. The American journal of clinical nutrition 2015;102(6):158594.

6. Latunde Dada GO. Iron metabolism in athletes-achieving a gold standard. European journal of haematology 2013;90(1):10-5.

7. Peeling P, Dawson B, Goodman C, Landers G, Trinder D. Athletic induced iron deficiency: new insights into the role of inflammation, cytokines and hormones. European journal of applied physiology 2008;103(4):381.

8. Peeling P. Exercise as a mediator of hepcidin activity in athletes. European Journal of Applied Physiology 2010;110(5):877-83.

9. Pasricha S-R, Low M, Thompson J, Farrell A, De-Regil L-M. Iron supplementation benefits physical performance in women of reproductive age: a systematic review and meta-analysis. The Journal of nutrition 2014;144(6):906-14.

10. Davies K, Donovan CM, Refino C, Brooks GA, Packer L, Dallman PR. Distinguishing effects of anemia and muscle iron deficiency on exercise bioenergetics in the rat. American Journal of PhysiologyEndocrinology and Metabolism 1984;246(6):E535-E43.

11. Davies K, Maguire J, Brooks G, Dallman P, Packer L. Muscle mitochondrial bioenergetics, oxygen supply, and work capacity during dietary iron deficiency and repletion. American Journal of Physiology-Endocrinology and Metabolism 1982;242(6):E418-E27.

12. Brownlie T, Utermohlen V, Hinton PS, Giordano C, Haas JD. Marginal iron deficiency without anemia impairs aerobic adaptation among previously untrained women. The American Journal of Clinical Nutrition 2002;75(4):734-42.

13. Hinton $P$, Sinclair L. Iron supplementation maintains ventilatory threshold and improves energetic efficiency in iron-deficient nonanemic athletes. European Journal of Clinical Nutrition 2007;61(1):30-9.

14. Mukaka MM. A guide to appropriate use of correlation coefficient in medical research. Malawi Medical Journal 2012;24(3):69-71.

15. Penninx BW, Pahor M, Cesari M, Corsi AM, Woodman RC, Bandinelli $\mathrm{S}$, et al. Anemia is associated with disability and decreased physical performance and muscle strength in the elderly. Journal of the American Geriatrics Society 2004;52(5):719-24.

16. Burden RJ, Pollock N, Whyte GP, Richards T, Moore B, Busbridge $\mathrm{M}$, et al. Impact of intravenous iron on aerobic capacity and iron metabolism in elite athletes. Med Sci Sports Exerc 2014;47(7):1399407.
17. Waldvogel S, Pedrazzini B, Vaucher P, Bize R, Cornuz J, Tissot J-D, et al. Clinical evaluation of iron treatment efficiency among nonanemic but iron-deficient female blood donors: a randomized controlled trial. BMC medicine 2012;10(1):8.

18. Garvican LA, Saunders PU, Cardoso T, Macdougall IC, Lobigs LM, Fazakerley $\mathrm{R}$, et al. Intravenous iron supplementation in distance runners with low or suboptimal ferritin. Medicine and Science in Sports and Exercise 2014;46(2):376-85.

19. Dellavalle DM, Haas JD. Iron supplementation improves energetic efficiency in iron-depleted female rowers. Medicine and Science in Sports and Exercise 2014;46(6):1204-15.

20. Friedmann B, Weller $E$, Mairbaurl $H, B$ Ärtsch P. Effects of iron repletion on blood volume and performance capacity in young athletes. Medicine and Science in Sports and Exercise 2001;33(5):741-6.

21. Schumacher $Y$, Schmid A, König D, Berg A. Effects of exercise on soluble transferrin receptor and other variables of the iron status. British Journal of Sports Medicine 2002;36(3):195-9.

22. Voss S, Alsayrafi M, Bourdon P, Klodt F, Nonis D, Hopkins W, et al. Variability of serum markers of erythropoiesis during 6 days of racing in highly trained cyclists. International Journal of Sports Medicine 2014;35(02):89-94.

23. Dickson $D$, Wilkinson $R$, Noakes T. Effects of ultra-marathon training and racing on hematologic parameters and serum ferritin levels in well-trained athletes. International Journal of Sports Medicine 1982;3(02):111-7.

24. Buratti P, Gammella E, Rybinska I, Cairo G, Recalcati S. Recent advances in iron metabolism: relevance for health, exercise, and performance. Med Sci Sports Exerc 2015;47(8):1596-604.

25. Hinton PS. Iron and the endurance athlete. Applied Physiology, Nutrition, and Metabolism 2014;39(9):1012-8.

26. Jacobs RA, Rasmussen $P$, Siebenmann C, Díaz V, Gassmann $M$, Pesta $D$, et al. Determinants of time trial performance and maximal incremental exercise in highly trained endurance athletes. Journal of Applied Physiology 2011;111(5):1422-30.

27. Reinke S, Taylor WR, Duda GN, von Haehling S, Reinke P, Volk $H-D$, et al. Absolute and functional iron deficiency in professional athletes during training and recovery. International Journal of Cardiology 2012;156(2):186-91.

28. Crouter SE, DellaValle DM, Haas JD. Relationship between physical activity, physical performance, and iron status in adult women. Applied Physiology, Nutrition, and Metabolism 2012;37(4):697705. 